\title{
CoRPOS QUe AMEAÇAM, CORPOS INSTRUMENTALIZADOS: RAÇA E GÊNERO NO DEBATE PÚBLICO SOBRE IMIGRAÇÃO NA ITÁLIA
}

\author{
Fernanda Di Flora GARCIA* \\ João Carlos Soares ZUIN
}

\begin{abstract}
RESUMO: O debate público sobre a imigração na Itália tem sido marcado, desde a década de 1990, pela vinculação entre o racismo popular e o racismo institucional, assim como por diversas expressões de sexismo. As vozes que destoam do paradigma securitário em curso têm sido alvo constante de ataques tanto de movimentos sociais da direita, quanto de partidos e expoentes políticos, e o alvo preferencial destes ataques tem sido as mulheres que ocupam cargos políticos proeminentes e atuam em prol dos direitos fundamentais dos imigrantes, como é o caso de Laura Boldrini e de Cècile Kyenge. Também as mulheres migrantes têm sido alvo de discursos e práticas xenófobas e racistas, articulados com a misoginia e o sexismo. Assim, o objetivo deste artigo é analisar as múltiplas formas de mobilização do racismo, do sexismo e da instrumentalização da violência de gênero, apontando para a construção dos estereótipos sobre os corpos considerados perigosos no debate sobre imigração na Itália.
\end{abstract}

PALAVRAS-CHAVE: Racismo. Violência de gênero. Imigração. Itália.

Introdução: a presença do repertório fascista nos discursos e práticas da Liga

O objetivo deste artigo é compreender e analisar o sentido e o significado das manifestações políticas vexatórias, sexistas e racistas que circulam no interior

\footnotetext{
UNICAMP - Universidade Estadual de Campinas. Campinas - SP - Brasil. 13083-896 - ferdiflora@ uol.com.br. https://orcid.org/0000-0003-4997-8651.

* UNESP - Universidade Estadual Paulista "Júlio de Mesquita Filho". Faculdade de Ciências e Letras de Araraquara. Programa de Pós-Graduação em Ciências Sociais. Araraquara - SP - Brasil. 14800-901 joao.cs.zuin@unesp.br. https://orcid.org/0000-0003-2397-3422.
} 
do debate público sobre imigração, em especial aquelas efetuadas por lideranças do partido político italiano Liga $^{1}$ contra mulheres imigrantes de origem árabe, latina e africana e mulheres italianas envolvidas diretamente em ações políticas de acolhimento dos imigrantes e defesa da universalização dos direitos humanos fundamentais, especialmente Cécile Kyenge ${ }^{2}$ e Laura Boldrini ${ }^{3}$. Pretendemos evidenciar como as palavras feitas para ferir (DE MAURO, 2017), de caráter violento e grande força performativa, constituem hoje parte significativa de continuidade de uma política estatal que exclui todos aqueles considerados como não-pessoas.

Nesse sentido, este artigo aborda a mobilização do sexismo por meio dos seguintes elementos: pela promoção de uma linguagem vulgar através da difusão dos discursos públicos da Liga; a referência à virilidade como força necessária para reconstrução da nação; a racialização do sexismo e a etnicização dos estupros; a revolução do bom senso por meio da retomada da defesa da família tradicional e heteronormativa; a evocação da violência sexista e do estupro como punição necessária e o combate à ideologia de gênero. Todos estes elementos se articulam no contexto do debate sobre a imigração, de modo que é possível observar as variadas formas de controle social marcadas pela intersecção entre gênero e raça, analisadas a seguir.

As sucessivas manifestações racistas e sexistas efetuadas por membros do partido que hoje representa a principal força da nova direita e do populismo na Itália tais como Roberto Calderoli (Senador da República) e Matteo Salvini (Secretário Geral da Liga, Ministro do Interior e Eurodeputado), expressas em discursos parlamentares, postagens nas redes sociais, cartazes, panfletos e charges evidenciam a articulação entre o racismo popular e o racismo institucional, o sexismo, a homofobia e a xenofobia, e possibilitam uma ampla percepção do avançado processo de proliferação do populismo emotivo (HOCHSCHILD, 2016; ILLOUZ, 2017; DAL LAGO, 2017), das palavras de ódio (DE MAURO, 2017; ANTONELLI, 2017; SARACENO, 2016) e da política do medo (DAL LAGO, 2004, 2017; RIVERA, 2009, 2010; MASTROPAOLO, 2005; FERRAJOLI, 2009, 2011; BASSO, 2011) cujos alvos principais são os corpos que ameaçam as fronteiras simbólicas e imaginárias relacionadas à pureza do sangue, da nação, da pele clara e da família nuclear

\footnotetext{
1 Partido que até o ano de 2017 utilizava o nome e o símbolo Liga Norte, evocando imagens identitárias e separatistas, mas cuja simbologia foi alterada com o objetivo ampliar sua imagem e obter consenso eleitoral ao nível nacional. Embora não seja tema deste artigo, é importante observar que a "virada patriótica" foi uma das estratégias mobilizadas por Matteo Salvini em direção a um consenso eleitoral nacional, evocando a força xenófoba como vocação nacional: "prima gli italianil".

2 Deputada e Ministra das pastas da Integração e da Política Juvenil no Governo Letta nos anos de 2013 e 2014, atualmente Eurodeputada.

3 Alta Comissária para os Refugiados da Organização das Nações Unidas nos anos de 1998 e 2012, Deputada e Presidente da Câmara dos Deputados nos anos de 2013-2018, reeleita Deputada na eleição de 2018.
} 


\section{Corpos que ameaçam, corpos instrumentalizados: raça e gênero no debate público sobre imigração na Itália}

tradicional, isto é, aquelas subjetividades que emergiram na cena pública, reivindicando direitos sociais, civis e políticos.

A utilização da retórica sexista, racista, agressiva e vulgar nos discursos da Liga está presente desde 1989, quando o fundador do partido, Umberto Bossi, desenvolveu uma nova estratégia política baseada, por um lado, na ruptura do decoro e dos ritos da política tradicional e, por outro, na utilização da linguagem clara e simples, popular e dialetal, sarcástica e vulgar, hostil e agressiva contra os inimigos da Padânia (DEMATTEO, 2011) ${ }^{4}$. No que toca ao sexismo presente na linguagem política da Liga, em inúmeras ocasiões o partido expressou - e expressa - um ideário machista baseado em uma pretensa virilidade defendida sob o slogan "celodurismo", que evoca o estilo político mussoliniano (RIVERA, 2009).

Conforme destaca Nicoletta Poidimani (2009), a construção do "super-homem fascista" evocava uma virilidade nunca colocada em questão, o pai de uma prole numerosa, dotado de coragem e espírito de sacrifício em prol da nação. Vinculada a esta imagem, havia a construção simultânea das populações racializadas, especialmente no contexto do avanço da colonização da Etiópia, de modo que a proteção da raça italiana passava pela força do homem fascista em resistir à sexualidade das mulheres negras, vista como potente ameaça. Em tal contexto, ocorreu uma mudança simbólica, e, posteriormente, jurídica, diante da necessidade de desconstrução do imaginário sexual da conquista (terras e mulheres a serem desbravadas), de modo a controlar e disciplinar a vida sexual de soldados e colonos, protegendo, assim, a pureza da "raça". De todo modo, para o que nos interessa neste artigo, importa observar que ao longo de todo o período fascista a evocação do líder forte e viril foi uma constante, e, mutatis mutandis, é o dispositivo reiteradamente empregado pelos líderes populistas da Liga desde a década de 1990.

A ênfase na ideia do líder potente e viril, utilizada por Umberto Bossi no slogan político "La lega ce l'ha duro", é pautada em uma retórica de dupla intencionalidade: 1) aquela que ressalta a suposta fraqueza de seus adversários políticos, corrompidos pela ideologia e pelo comportamento sexual das elites cosmopolitas e 2) a exposição da Liga como a única força e potência política que está à altura dos problemas do tempo presente e é capaz de solucioná-los. O objetivo fundamental destas referências é restaurar uma ordem supostamente natural na qual haveria lugares marcados e estabelecidos segundo os papéis sexuais e raciais. Trata-se, sobretudo, de um processo político, social e cultural que objetiva a naturalização dos sistemas de hierarquização

\footnotetext{
4 A Padânia nunca existiu histórica ou geograficamente, mas a Liga criou, desde sua fundação, uma narrativa histórica e geográfica para justificar suas reivindicações políticas e territoriais, tratando-se sobretudo de uma construção política voltada, inicialmente, para emancipar as regiões que compõem o norte da Itália e formar um país.

5 "Paudurismo", evocando uma iconografia viril, masculinista.
} 
social, de "endurecer e renaturalizar as fronteiras raciais e sexuais" (GARBAGNOLI, 2018, n.p., tradução nossa $)^{6}$.

De acordo com a antropóloga Annamaria Rivera (2009, p.247, tradução nossa), a Liga transformou em linguagem política a "exibição genital", que "revela quais são as pulsões que se agitam no ventre masculinista, racista e fascistóide do nosso infeliz país" ". A Liga não manifesta apenas o sexismo e racismo retóricos, mas produz expedições punitivas, iniciativas políticas e legislativas, práticas administrativas locais e nacionais derivadas dos modelos mais clássicos de discriminação e racismo institucional. Quando o atual Ministro do Interior, Matteo Salvini, lançou, por exemplo, a "Operação Praias seguras", cujo objetivo era combater a atividade ilegal, o contrabando e o comércio "abusivo" efetuado por estrangeiros, seguiu-se rapidamente um incremento nas atividades das rondas de cidadãos de grupos neofacistas como o Casa Pound e ataques arbitrários e violentos contra imigrantes.

É importante observar que na Itália republicana, até o advento da Liga, havia certo pudor em admitir que temáticas racistas, sexistas e homofóbicas típicas do período fascista fossem professadas ao nível institucional (BURGIO, 2001; POIDIMANI, 2009). Contudo, desde a sua aparição na cena política nacional, e especialmente diante do fato de que muitos de seus expoentes são provenientes da extrema direita fascista, como é o caso de Mario Borghezio, o cenário foi radicalmente alterado, promovendo paulatinamente a legitimação institucional do racismo e pavimentando o caminho para a emergência de partidos e movimentos que hoje defendem abertamente o legado de Mussolini, como é o caso do partido Casa Pound ${ }^{9}$. Assim, de Umberto Bossi até Matteo Salvini, a Liga manteve a linguagem política baseada na vulgaridade, na desqualificação de opositores, no sexismo e no racismo, com a característica linguística e política da composição de frases simples, da redação elementar, do uso de palavras obscenas e vulgares, das ofensas pessoais sem limites aos políticos adversários transformados em inimigos.

Contudo, há um evidente salto de qualidade na forma como o atual líder da Liga aparece e efetua sua comunicação política: o permanente uso dos meios digitais, a contínua instrumentalização da linguagem simultaneamente emotiva e agressiva, a disseminada utilização de emojis pops e, sobretudo, a reafirmação diária da sua imagem através da técnica comunicativa da storytelling (SALMON, 2008). As novas formas de comunicação na era digital proporcionam ao líder da Liga a ampliação do espaço das palavras de ódio que, uma vez postadas e, posteriormente, comentadas e repostadas pelos cidadãos-seguidores, alcançam uma disseminação sempre mais

6 "Durcir, renaturaliser les frontières raciales et sexuelles" (GARBAGNOLI, 2018, n.p.).

7 "l'esibizione genitale" (RIVERA, 2009, p.247).

8 "rivela quali siano le pulsioni che se agitano nel ventre maschilista, razzista e fascistoide del nostro infelice paese" (RIVERA, 2009, p.247).

9 Cujo dirigente, Alberto Palladino, recentemente afirmou que "no coração de todo italiano há um espacinho para o fascismo" (BERCITO, 2018, n.p.). 


\section{Corpos que ameaçam, corpos instrumentalizados: raça e gênero no debate público sobre imigração na Itália}

ampla e capilar na mentalidade e no comportamento das pessoas, estratégias sobre as quais voltaremos a tratar de modo detido ao longo deste artigo. À luz dos elementos brevemente expostos, a escolha do estudo dos casos Kyenge e Boldrini se justifica pelos seguintes elementos fundamentais: 1) a Itália é o principal laboratório político da luta contra imigração, na qual foram introduzidas sucessivas reformas jurídicas que resultaram na lei n.94 de 15 de Julho de 2009 que criminalizou o imigrante sem documento e institucionalizou a figura do "imigrante ilegal" (FERRAJOLI, 2009, 2011), 2) a Itália, desde a década de 1990, é o principal laboratório do fenômeno do populismo (TARCHI, 2015) construído por diversos atores e partidos políticos que alcançaram expressivos sucessos eleitorais através da retórica agressiva e alarmista da suposta invasão de imigrantes e da islamização da cultura italiana e europeia, do discurso xenofóbico e racista baseado na ideia da comunidade orgânica ameaçada em seus valores morais, tradições multisseculares e na enfática defesa da identidade e soberania nacional e 3) pelo fato de que a intersecção entre o racismo e o sexismo é ainda pouco debatida na Itália, sobretudo no contexto do fenômeno migratório.

\section{A intersecção entre raça e gênero no debate sobre o fenômeno migratório}

O fenômeno migratório na Itália tem sido o espaço privilegiado no qual é possível observar a intersecção entre raça, gênero e classe ${ }^{10}$, que se manifesta no debate público e cujas implicações atingem as mais diversas esferas da vida social, desde a estigmatização e produção de estereótipos até a discriminação jurídica, política, econômica e social, apontando para o fato de que a análise de tais convergências evidencia a impossibilidade de compreender e analisar as desigualdades presentes tanto na Itália quanto nas sociedades contemporâneas de forma isolada (BIROLI; MIGUEL, 2015; PISCITELLI, 2008). Nesse sentido, as teorias da interseccionalidades contribuem sobremaneira para a análise relativa aos nexos entre migração, raça, classe e gênero, já que, para além da condição comum, no caso aqui analisado, o fato de se tratar de ataques e discriminações direcionadas às mulheres, é preciso considerar, como aponta Bell Hooks (2014), que as distintas identidades de raça e classe produzem diferenças qualitativas sobre a vivência comum que as mulheres partilham. É possível, portanto, por meio desta ferramenta analítica, compreender os efeitos complexos que decorrem dos múltiplos

\footnotetext{
10 O termo "interseccionalidade" aparece pela primeira vez em um texto de Kimberlé Crenshaw, no final dos anos 1970, com o objetivo de elaborar uma crítica ao feminismo branco, de classe média, heteronormativo, que, de acordo com o feminismo negro emergente no período, desconsiderava as determinações de raça, gênero, classe e sexualidade na potencialização das múltiplas formas de opressão, apontando haver não apenas diferenças entre as mulheres, mas relações de privilégio.
} 
eixos de diferenciação que marcam os corpos e as vidas das mulheres em contextos específicos.

No que se refere a categoria "raça" e a pluralidade de definições analíticas para o termo racismo (CAMPOS, 2017), assim como para os termos "sexo" e "sexismo", é importante destacar que não podemos compreendê-las como dados naturais, mas como construções representativas sempre vinculadas às condições sociais concretas de conflitos e contradições. Com o intuito de evidenciar que a despeito do fato de a categoria "raça ser uma categoria imaginária aplicada a grupos humanos reais" (RIVERA, 2010, p.3, tradução nossa) ${ }^{11}$, não possuir valor científico, e, assim, ser paradoxal, por sua própria função ideológica, que estabelece rígidas hierarquias pretensamente naturais, ela pode ser utilizada para produzir novos consensos e mobilização social, possuindo, portanto, "uma performatividade social" (RIVERA, 2010) que condiciona a percepção sobre o outro.

Tal formulação ideológica incide sobre a realidade social modificando-a segundo os interesses materiais e imateriais dos grupos ou das classes sociais dominantes e, como destaca Achille Mbembe (2018, p.27), "a raça é ademais um complexo perverso, gerador de temores e tormentos, de perturbações do pensamento e de terror, mas sobretudo de infinitos sofrimentos e, eventualmente, de catástrofes". No caso italiano, os dispositivos ideológicos sexistas e racistas alcançaram o terror extremo da promoção da "necropolítica" contra os corpos dos sujeitos subalternizados, especialmente as mulheres e os imigrantes.

O sexismo, por seu turno, compreendido como um dispositivo que mobiliza uma imagem inferiorizada das mulheres em relação aos homens, legitimando práticas discriminatórias, produziu no âmbito da cultura positivista "uma teoria orgânica da inferioridade feminina, fundada sobre a invenção de nexos psíquicofísicos" (BURGIO, 2012, p.91, tradução nossa) ${ }^{12}$, análogos àqueles "construídos pelo discurso racista na invenção da "raça negra"' (BURGIO, 2012, p.91, tradução nossa) ${ }^{13}$, aproximando as mulheres da natureza, do mundo instintivo, da irracionalidade. Ainda que tal produção tenha sido desconstruída ao longo do tempo, seus efeitos ainda se fazem sentir de forma mais ou menos explícita e incidem diretamente sobre as representações contemporâneas acerca do papel das mulheres (SCOTT,1995). Nesse sentido, o sexismo opera com um caráter análogo ao do racismo na medida em que cria o gênero feminino em função da dominação masculina (BOURDIEU, 2002).

$\mathrm{Na}$ Itália, as populações racializadas variam ao longo do tempo, implicando em tratamentos diferenciais, de modo que o racismo contemporâneo naturaliza as

\footnotetext{
11 "Ia razza è una categoria immaginaria applicata a gruppi umani realli"(RIVERA, 2010, p.03).

12 "una teoria organica dell'inferiorità femminile, fondata sull'invenzione di nessi psico-fisici"(BURGIO, 2012, p.91).

13 "costruiti dal discorso razzista nell'invenzione dela 'razza negra'”(BURGIO, 2012, p.91).
} 


\section{Corpos que ameaçam, corpos instrumentalizados: raça e gênero no debate público sobre imigração na Itália}

diferenças sociais, culturais, religiosas, concebidas como absolutas, a-históricas, imutáveis, ao passo em que este neorracismo se vincula ainda com o sexismo, estabelecendo um sistema de desigualdades jurídicas, econômicas e sociais e uma pluralidade de estratégias de exclusão que recaem especialmente sobre as mulheres (RIVERA, 2010). Mas se a população racializada, na Itália, varia ao longo do tempo, podemos observar que a violência contra as mulheres também é instrumentalizada com finalidade política: ainda que agressões contra as mulheres sejam transversais, que independam de status, classe e nacionalidade, ocorrendo em múltiplos espaços sociais, o tema da violência masculina sobre as mulheres recebe grande ênfase quando os protagonistas são os homens estrangeiros, reforçando, assim, os discursos que imputam a incivilidade, a barbárie ao sujeito estrangeiro, sobretudo de origem árabe e africana, como se a violência sexista e misógina constituísse uma característica ontológica destes sujeitos. As campanhas políticas e midiáticas ignoram sistematicamente que a violência sexista na Itália é endêmica, ao passo em que o país ocupa a $84^{\circ}$ posição em uma lista de 128 países nos quais a violência contra a mulher alcança níveis elevados, abaixo de países como Filipinas $\left(6^{\circ}\right)$, Sri Lanka $\left(15^{\circ}\right)$ e África do Sul $\left(20^{\circ}\right)$. Contudo, a etnicização do estupro e da violência contra as mulheres, de modo geral, são funcionais ao racismo e são assim representados na mídia, nos discursos políticos e populares.

Raça e sexo remetem, neste contexto, ao discurso que avalia os seres humanos como grupos naturais, reificados e transformados em coisas (COROSSACZ, 2013), funcionando sobre o mesmo mecanismo de atribuição de um local social a partir de elementos que essencializam o grupo, de modo que aquilo que torna comum o racismo e o sexismo não é o fato de serem duas formas de opressão ou de violência, mas o fato de que estas formas de opressão são vistas como o êxito inevitável de uma diferença natural entre os grupos (COROSSACZ, 2013; SARACENO, 2016).

Contudo, apesar de tal articulação, prevalece no país uma dificuldade histórica em admitir tanto a existência do racismo, que se fundamenta no mito do italiano "brava gente", supostamente não maculado pela experiência colonial, quanto a existência do sexismo e do machismo, profundamente arraigados na sociedade italiana (RIVERA, 2010; COROSSACZ, 2013; SARACENO, 2016). Predomina o entendimento de que uma igualdade formal é suficiente para garantir uma sociedade não sexista, imputando ao outro, particularmente ao estrangeiro, o lugar do mundo "incivilizado, pré-moderno", marcado pela violência sistemática contra as mulheres, racializando o sexismo.

Paradoxalmente, ainda que os expoentes políticos membros da Liga evoquem a racialização do sexismo (RIVERA, 2010), uma das primeiras medidas de Matteo Salvini ao assumir o cargo de Ministro do Interior foi afirmar, em seu primeiro discurso ministerial, que havia estabelecido duas prioridades políticas em nome de seu projeto de "revolução do bom senso": a luta contra a imigração e a proteção da 
família formada "por uma mãe e um pai". Salvini evoca reiteradas vezes o espectro daquilo que denomina de "ideologia de gênero", buscando bloquear qualquer empreendimento político, jurídico ou cultural que defenda a desnaturalização da ordem sexual ${ }^{14}$, mobilizando, simultaneamente, uma onda populista de pânico moral em torno da criança a ser protegida (GARBAGNOLI, 2018) e do papel social esperado e atribuído às mulheres: reprodutora, mãe, esposa, restrita ao espaço doméstico e à vida privada.

Figura 1: Propagandas do Forza Nuova (Imagem 1), Lega Nord (Imagens 2 e 3).

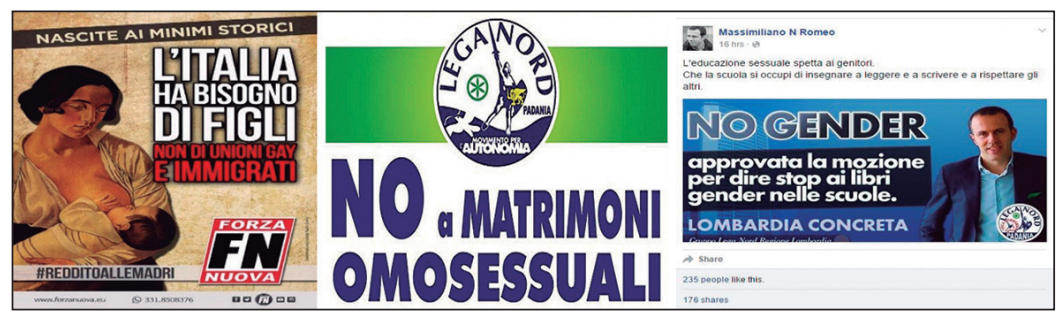

Fonte: Páginas oficiais dos Partidos Forza Nuova no Facebook e Lega Nord no Twitter; Twitter Massimiliano N Romeo, Lega Nord.

Os discursos e estratégias políticas mobilizados por Salvini e demais membros da Liga, bem como de outros partidos de extrema direita, pretendem endurecer e renaturalizar as fronteiras raciais e sexuais (GARBAGNOLI, 2018). Nesse sentido, os diversos casos cotidianos de ofensas verbais, agressões físicas, discriminações e racismo, que crescem no ritmo das devastadoras crises econômicas e políticas, expressam as conexões entre os fenômenos do populismo político, da imigração em massa e do avanço do racismo e da misoginia na sociedade italiana. A investigação de tais fenômenos sociais através das manifestações estéticas e políticas produzidos pela Liga revela a presença de novos dispositivos de desumanização das minorias e sua paralela transformação política em não-pessoa e inimigo (DAL LAGO, 2004; BURGIO, 2001, 2012).

Trata-se de um dilema que acompanha o curso da modernidade, conforme apontou o jurista italiano Antonio Cassese (2005) acerca do declínio dos direitos humanos e da difusão do nacionalismo agressivo e violento que, novamente, produz a construção social do outro que não sendo reconhecido como humano em sua plenitude, é transformado em inimigo. Contudo, é muito importante compreendermos como a utilização política da linguagem do ódio (hate speech) foi

\footnotetext{
${ }^{14}$ Emblemático nesse sentido é o caso do filósofo político italiano Stefano Rodotà. Candidato à Presidência da República Italiana em 2013, foi violentamente atacado por seus opositores, especialmente da Liga, em função de sua longa defesa pública dos direitos para os grupos sociais discriminados e minoritários na Itália: mulheres, homossexuais, família homoafetiva, estrangeiros.
} 


\section{Corpos que ameaçam, corpos instrumentalizados: raça e gênero no debate público sobre imigração na Itália}

capaz de promover, em um curto espaço de tempo, duas profundas transformações na realidade social: a neutralização nos indivíduos e cidadãos do pudor e da vergonha que até pouco tempo coibia e impedia as manifestações verbais da discriminação, da xenofobia e do racismo e a destruição da memória histórica e política construída na segunda metade do século XX que, após a revelação da violência extrema do fascismo e do nazismo, forjou os pilares dos direitos humanos fundamentais e dos direitos sociais e econômicos: o direito à identidade e à liberdade, o respeito e a dignidade existente em toda vida humana (RODOTÀ, 2012).

\section{As agressões racistas e sexistas contra as mulheres imigrantes}

As mulheres imigrantes, sobretudo aquelas de origem africana, latina e árabe, sofrem ataques constantes que evocam o repertório do passado colonial e as representações racistas acerca dos corpos das mulheres negras. Tornou-se comum no discurso popular, por exemplo, a substituição da palavra "prostituta" pela palavra "nigeriana", ao mesmo tempo em que a mídia difunde imagens com o objetivo de reforçar uma suposta "hipersexualidade" das mulheres de origem africana (ANGEL-AJANI, 2000) difundindo ainda imagens relativas a uma espécie de "super fertilidade" das mulheres estrangeiras para barrar o direito à reunificação familiar e criticar as políticas sociais que supostamente privilegiariam os filhos de migrantes em detrimento dos nativos.

Outro aspecto importante que evidencia "um formidável exemplo de racismo e sexismo institucional" 15 (PETTENÒ, 2011, p.539, tradução nossa) pode ser observado na ausência de referência às violências sofridas pelas mulheres migrantes nos relatórios governamentais, sobretudo aquelas que são levadas à prostituição, como demonstrado, entre outros, no Rapporto sulla criminalità in Italia elaborado pelo Ministério do Interior em 2007. O relatório desconsidera as violências sofridas pelas prostitutas de origem estrangeira, considerando apenas as violências cometidas contra as mulheres italianas, uma vez que "a grande maioria dos clientes é branca e italiana enquanto a grande maioria das mulheres prostituídas é 'de cor' e imigrada, de modo que aquilo que se consuma a cada noite nas ruas italianas é um verdadeiro estupro étnico de massa" ${ }^{16}$ (PETTENÒ, 2011, p.539, tradução nossa).

Em seus estudos sobre migrações e gênero em Portugal e Itália, a antropóloga Adriana Piscitelli (2008) afirma que as imigrantes de origem latina, em especial as brasileiras, são racializadas como mulatas e, assim, sexualizadas, como corpos

\footnotetext{
15 "formidabile esempio di razzismo e sessismo istituzionali" (PETTENÒ, 2011, p.539).

16 "siccome la stragrande maggioranza dei clienti è bianca e italiana mentre la grande maggioranza delle donne prostituite è 'colorata' e immigrata, quello che si consuma ogni notte sulle strade italiane è un vero e proprio stupro 'etnico' di massa” (PETTENÒ, 2011, p.539).
} 
disponíveis, erotizados. A figura da mulata, de acordo com a célebre análise de Lélia González (2019), representa não apenas o mito da democracia racial, mas "exerce sua violência simbólica de maneira especial sobre a mulher negra", já que o outro lado da sexualização se materializa no cotidiano dessas mulheres, quando ocupam os lugares subalternos. Para González (2019, p.242), esses dois aspectos implicam doses extremas de agressividade, de modo que "os termos mulata e doméstica são atribuições de um mesmo sujeito", a depender da ótica a partir da qual são vistas. $\mathrm{Na}$ Itália, o discurso colonial que apresentou historicamente as mulheres das ex-colônias como hipersexualizadas ainda é mobilizado, e as mulheres imigrantes são associadas também ao mercado do sexo, à prostituição, ao corpo que pode ser consumido, dando lugar às múltiplas formas de violência, físicas e simbólicas.

Exemplo da materialização destas formas de violência ocorreu na cidade de Trento, norte da Itália e fronteira com a Áustria. Tradicionalmente, no mês de maio ocorre a festa popular que celebra as ações dos Alpinos, um corpo militar montanhês de defesa das fronteiras do norte da Itália, na qual são relembradas as batalhas na Primeira Guerra Mundial. No curso das festividades ocorridas em maio de 2018, diversas mulheres sofreram desrespeitos, abusos, violências físicas, agressões verbais, tentativas de estupro. Em Trento, estes casos possuem um elemento extremamente importante, relatado por mulheres que estavam trabalhando nas cantinas e hospedagens como garçonetes e camareiras. Na página do Facebook "Nem uma a menos Trento", diversas jovens relataram que sofreram violências físicas e verbais, dentre elas, uma jovem garçonete morena que testemunhou e sofreu as seguintes agressões no bar em que trabalhava: "estes negros de merda", "não sou racista, mas...", "que voltem todos para suas casas", "mataria todos", "tire as tetas para fora", "bela gostosa venha aqui”, "que bela morena, faça-me uma chupeta", "não quero ser servido por uma marroquina" e sintetizou as agressões dizendo: "Me senti injustamente violentada e impotente, violentada pelos olhares, pelos comentários sexistas, pelas apalpadas, pela exotização do meu corpo transformado em objeto sexual, que desperta odores de violência tropical e nostalgias coloniais" (SCIUTO, 2018, n.p., tradução nossa) $)^{17}$.

É importante observar, como sustenta Nicoletta Poidimani (2009, p.07-08, tradução nossa), que "os velhos e experimentados dispositivos racistas e desumanizantes que se formaram justamente nos cinquenta anos da experiência colonial na África são reativados hoje sobre a pele de mulheres e homens migrantes, em nome da segurança" ${ }^{\prime 18}$. Enquanto no período colonial a posse do corpo das mulheres negras

\footnotetext{
17 "Mi sono sentita ingiustamente violentata ed impotente, violentata dagli sguardi, dai commenti sessisti, dalle palpate, dal esotizzazione continua del mio corpo trasformato in oggetto sessuale che risveglia profumi di violenza tropicale, nostalgie coloniali" (SCIUTO, 2018, n.p).

18 "vecchi e sperimentati dispositivi razzisti e de-umanizzanti che si formarono proprio nei cinquant'anni dell'esperienza coloniale in Africa si riattivano oggi sulla pelle di donne e uomini migranti, in nome della sicurezza" (POIDIMANI, 2009, p;07-08).
} 


\section{Corpos que ameaçam, corpos instrumentalizados: raça e gênero no debate público sobre imigração na Itália}

coincidia com a conquista colonial, este fato servia também como um instrumento eficaz de recrutamento das tropas. Na construção social do racismo italiano, o corpo das mulheres negras era associado à exploração sexual e ao corpo das mulheres brancas, italianas, era reservado o papel de proteção do sangue, de modo que, ao proclamar em 1936 o Império Italiano da África Oriental, Mussolini consolidou o racismo de Estado ao sancionar dispositivos jurídicos que demarcavam claramente a distância entre os cidadãos e os súditos, cabendo às mulheres italianas a defesa do patrimônio genético da raça, sob o risco de serem rebaixadas ao papel de súditas no caso de envolvimento com os colonos. Estes dispositivos jurídicos que pressupunham a não-mistura buscavam também expropriar as mulheres do controle sobre sua própria fecundidade, sendo consolidados na defesa do ius sanguinis (POIDIMANI, 2013). Da hipersexualização e das representações das mulheres negras como metáfora de um corpo-território a ser dominado, se passa paulatinamente à criminalização das relações mistas e à animalização das mulheres africanas.

Assim, a referência ao passado a partir de um olhar para o presente permite compreender como o papel atribuído às mulheres nativas e estrangeiras durante o período colonial e o império fascista ainda ecoa nas relações sociais no país, uma vez que a mentalidade racista e patriarcal contribuiu para uma espécie de regime de segregação racial que não se restringe ao passado, uma vez que "quando não possuem os documentos em ordem, as mulheres imigrantes são corpos estranhos, invisíveis, fora das normas, sobre as quais o macho italiano reivindica o poder de abusar e que, uma vez explorada, devem ser expulsas ou confinadas"19 (SABELLI, 2012, p.147, tradução nossa).

\section{A racialização do sexismo}

No contexto das múltiplas formas de mobilização do sexismo e da violência de gênero, é sintomático o nexo entre as medidas legislativas antiestupro, a instrumentalização do corpo feminino e o racismo direcionado à população migrante. Em 2009, por exemplo, no quadro da difusão de uma série de medidas emergenciais adotadas pelo governo italiano no "Decreto Segurança", foi promulgada a "emergência estupros", estabelecendo que as mulheres italianas precisavam ser defendidas dos "imigrantes estupradores", nada falando a respeito da violência promovida pelos autóctones. Em mais uma medida populista, o primeiro ministro Silvio Berlusconi, com apoio da Liga Norte, sancionou normas e "Medidas urgentes em matéria de segurança pública e combate à violência sexual" que previam a

19 "quando non hanno i documenti in regola, le donne immigrate sono corpi estranei, invisibili, fuori dalla norma, su cui il maschio italiano rivendica il potere di abusare e che, una volta sfruttati, devono essere espulsi o confinati" (SABELLI, 2012, p.147). 
expulsão de imigrantes, vinculando a violência sexual ao controle do território. Neste dispositivo ficou evidenciado o uso instrumental da violência de gênero e do corpo feminino para legitimar os instrumentos securitários, no mesmo momento em que se alterou a Legge Merlin, que transformou em crime a prostituição. No cenário da racialização do sexismo, são difundidas inúmeras imagens, panfletos e cartazes virtuais, não apenas estigmatizando os imigrantes como estupradores em potencial, mas igualmente evocando o passado fascista, como podemos observar abaixo:

Figura 2: Imagens estigmatizando os imigrantes como estupradores em potencial

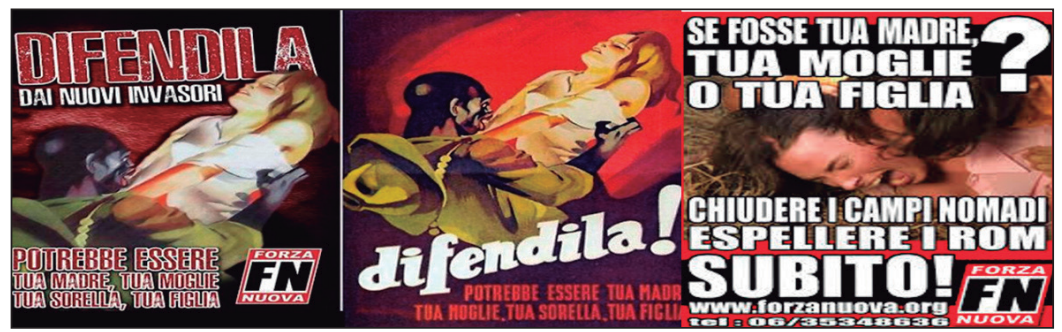

Fonte: Disponível em: http://www.liberoquotidiano.it/news/italia/13227508/forzanuova-manifesto-stupri-fascismo-razzismo-repubblica-sociale-italiana.html.

A primeira imagem é uma adaptação de um cartaz produzido durante o fascismo, baseado numa iconografia habitual dos colonos, hoje representados pela figura do imigrante. Se a mulher estrangeira aparece como aquela disponível aos nativos, os homens estrangeiros, por sua vez, representam os corpos ofensivos, que trazem risco às mulheres da nação, reforçando a ideia de que as mulheres precisam ser protegidas, uma vez que seriam mais frágeis. A permanente ameaça ao corpo da mulher branca é utilizada tanto para legitimar o racismo contra os imigrantes quanto a própria ideia do risco evoca elementos importantes do fascismo e de discursos racistas de matriz colonial, como a necessidade de proteção da raça (estabelecida juridicamente durante o governo Mussolini) e a atribuição aos corpos negros de uma força instintiva que os impediria de conter as pulsões sexuais, de modo que o problema da violência sexual converte-se em um problema da segurança do território.

$\mathrm{O}$ uso do pronome possessivo é extremamente revelador da fortíssima mentalidade machista, patriarcal e patrimonial, que se sente ameaçada pela presença de outros homens. Como afirmou a socióloga italiana Chiara Saraceno, os movimentos anti-imigração e anti-islamismo e os partidos da nova direita, são "pouco ou nada sensíveis às moléstias e agressões que as mulheres europeias e ocidentais sofrem em seus próprios países (uma sobre três, segundo os últimos dados de Eurostat)"20

20 "poco o per nulla sensibile alle molestie e aggressioni che le donne europee e occidentali subiscono nei propri Paesi (una su tre, secondo gli ultimi dati Eurostat)" (SARACENO, 2016a, n.p.). 


\section{Corpos que ameaçam, corpos instrumentalizados: raça e gênero no debate público sobre imigração na Itália}

(2016a, n.p., tradução nossa), mas levantam suas vozes quando tais agressões são cometidas por estrangeiros.

\section{A Liga e os casos Cécile Kyenge e Laura Boldrini}

Tullio de Mauro (2017), o famoso linguista italiano do século XX, no relatório intitulado Palavras para ferir, solicitado por Laura Boldrini na Comissão "Jo Cox" sobre a intolerância, a xenofobia, o racismo e os fenômenos de ódio ${ }^{21}$, elencou a imensa variedade de palavras de ódio (hate speech) disseminadas na cultura italiana contemporânea e dirigidas para as pessoas, grupos e classes identificados como ameaçadores, inferiores e perigosos. Muitas das palavras elencadas por De Mauro (2017) compõem a linguagem política da Liga desde a sua fundação até o recente sucesso eleitoral. Para o linguista Giuseppe Antonelli (2017, p.77, tradução nossa), a "vulgar eloquência" da linguagem política contemporânea comporta estereótipos negativos, insultos e desprezos que "de Bossi a Salvini, de Berlusconi a Grillo, é sempre mais presente e frequente o uso da palavra obscena" que "não somente foi inflacionada, mas está quase institucionalizada"22. A força das palavras obscenas e vulgares do discurso político populista atinge as emoções, os sentimentos, as pulsões profundas dos indivíduos, ao mesmo tempo, que mobiliza a percepção e o intelecto dos cidadãos em direção dos inimigos internos e externos apontados como culpados pelas crises que assolam a sociedade italiana.

No curso das graves crises econômicas, políticas e culturais que a Itália atravessava após 2008 e 2010, que resultaram na destituição de Berlusconi do cargo de premiê, os governos ocupados por atores técnicos e políticos promoveram diversas reformas, dentre elas, no governo de Enrico Letta (de abril de 2013 a fevereiro de 2014) a nomeação de Cécile Kyenge para ocupar a pasta ministerial da Integração. O governo Letta buscava promover duas mensagens políticas em meio aos gravíssimos acontecimentos diários de imigrantes afogados no Mar Mediterrâneo, desembarque contínuo de novos imigrantes, acirramento da xenofobia, do racismo e do sexismo: a nomeação de uma mulher e de uma mulher de cor de pele negra. A nomeação de Kyenge foi alvo imediato de manifestações preconceituosas e racistas por membros da Liga Norte, seja na forma de comentários nas postagens em seus sites, seja na forma de charges e pôsteres usados imediatamente como propaganda política.

\footnotetext{
${ }^{21}$ Trata-se da primeira comissão realizada na União Europeia após o brutal assassinato da Deputada britânica Jo Cox em 16/06/2016 por um britânico devido às posturas a favor da imigração e dos direitos humanos fundamentais.

22 "volgare eloquenza"; "da Bossi a Salvini, da Berlusconi a Grillo, il turpiloquio è diventato sempre più presente e frequente" e "non solo inflazionato, ma quase istituzionalizzato"(ANTONELLI, 2017, p.77).
} 
Um pôster, em especial, merece atenção pela construção semântica e simbólica que, utilizando a expressão "Se isto é um ministro...", modifica o título de Primo Levi "Se questo è un 'uomo", no qual testemunhava os horrores do nazismo escrito pelo sobrevivente de Auschwitz. A utilização do título do livro que narrava os processos de desumanização sofridos pelos judeus, comunistas, eslavos, ciganos, homossexuais, dissidentes políticos expressa duas importantes manifestações políticas dos partidos da nova direita que compõem a extensa família do populismo contemporâneo: a destruição do passado e a neutralização do fascismo e do nazismo pelo revisionismo e pela relativização.

O título do cartaz também visava expor ao vexame a Ministra Kyenge que supostamente seria conivente com a clandestinidade, outra palavra que é neutralizada historicamente (os seres humanos que tiveram que viver na clandestinidade para sobreviver às leis raciais e à solução final do nazismo) e transformada pela semântica populista na figura do imigrante "ilegal", aquele que supostamente se esconde para poder agir de forma delinquente, perigosa, ameaçadora no cotidiano das cidades italianas. A criminalização da condição de imigrante sem documentos, sempre mais distante da possibilidade de conseguir obter o direito de asilo e o acesso à cidadania pelas sucessivas leis italianas, gerou a condição de clandestinidade que afeta a vida de milhares de pessoas na Europa desde a década de 1990.

O cartaz visa atingir os "instintos e as pulsões primárias"23 (ANTONELLI, 2017, p.8, tradução nossa) dos italianos e produzir uma mentalidade sempre mais avessa às figuras dos imigrantes e dos políticos que defendem seus direitos. A palavra de ordem "A clandestinidade é um crime!" foi e é um dos slogans repetidos permanentemente pelas lideranças políticas da Liga.

Figura 3: Pôster da Lega Nord

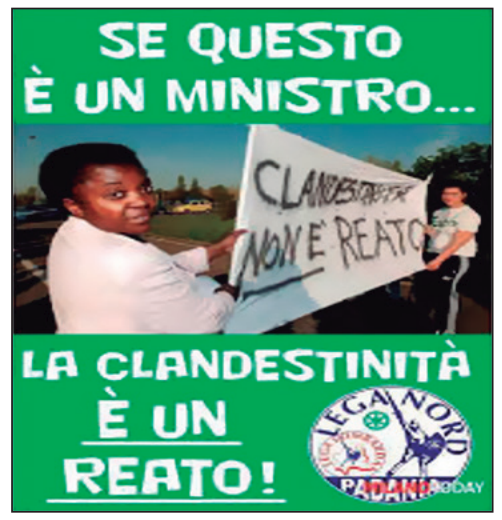

Fonte: Site oficial da Lega Nord no Facebook

23 "istinti e alle pulsioni primarie" (ANTONELLI, 2017, p.08). 


\section{Corpos que ameaçam, corpos instrumentalizados: raça e gênero no debate público sobre imigração na Itália}

Para Antonelli (2017), a linguagem política do populismo é caracterizada pelos seguintes elementos: a agressividade linguística que impossibilita o diálogo entre os grupos sociais; o aumento da distância entre as palavras e os fatos; a proliferação das frases feitas e breves, os slogans de alto impacto emotivo; o abuso do uso de palavras de uma ou duas sílabas, as promessas fabulosas de retorno à vida e ao status perdidos, o desrespeito e desprezo das outras forças políticas e pela agressividade e violência verbal, a discriminação e construção da figura do inimigo. A substituição do argumento e da ideia pela emoção produz uma língua política grosseira, simplista e agressiva que paralisa o debate político e promove o processo "des-democratização" da sociedade (BROWN, 2015).

Nesse contexto, o ponto extremo da linguagem política xenofóbica, racista e misógina ocorreu em 13 de julho de 2013, quando o Senador Roberto Calderoli, um dos políticos mais expressivos da Liga, em uma festa partidária, afirmou que "quando a vejo (Kyenge) não consigo deixar de pensar em um orangotango" (URBINATI, 2013, n.p., tradução nossa) ${ }^{24}$. A imediata repercussão da frase e os inúmeros protestos das forças sociais e políticas resultaram no pedido de desculpas à Ministra que, não obstante, protocolou a queixa de falta de decoro do Senador, cujo processo não resultou em sua cassação pelos senadores italianos, dado o argumento de que a frase não fora pronunciada no Senado e sua opinião não estaria vinculada com sua função de senador. A negligência e conivência política em absolver Calderoli em 2015 não é pior do que a justificativa do Senador em 2013: tratava-se de uma "piada", como aquela que as pessoas dizem no bar, nos encontros de família.

Lynda Dematteo (2011) em seu estudo acerca da Liga intitulado L'idiota in politica. Antropologia della Lega Nord, demonstra que o artifício dos atores políticos do partido em pronunciar ofensas, grosserias, vulgaridades, frases racistas e, posteriormente, afirmar que se tratava de uma mera piada, foi amplamente utilizado para subverter os códigos de conduta e moralidade da política tradicional e para promover ofensas a determinados atores políticos que rendiam amplos dividendos políticos nos eleitores conservadores. $\mathrm{O}$ uso da linguagem obscena e vulgar das piadas serve para efetuar a identificação plena e imediata entre o líder político e os indivíduos e cidadãos: falam e pensam da mesma forma, utilizando as mesmas palavras que a pessoa comum diz no "bar, no armazém, na barbearia, no círculo esportivo, no estádio, na praça, onde no domingo senta para conversar com os amigos" (TARCHI, 2015, p.251, tradução nossa) ${ }^{25}$.

Cécile Kyenge foi e continua sendo utilizada pelos políticos da Liga como alvo de agressões e vulgaridades, violências verbais e ameaças físicas. Simboliza o corpo que ameaça o machismo em seus principais espaços tradicionalmente

\footnotetext{
24 "quando la vedo non posso non pensare a um orango"(URBINATI, 2013, n.p.).

25 "il bar, il circolo sportivo, lo stadio, la piazza dove la domenica ci si ferma a chiacchierare con gli amici" (TARCHI, 2015, p.251).
} 
exclusivos de prestígio e poder: a profissão e a política. A visibilidade que alcançou como Ministra de duas pastas, deputada e eurodeputada, gerou a reação violenta da Liga e a reprodução das palavras de Calderoli nas postagens de diversos simpatizantes que continuam chamando-a de orangotango, prostituta e lançam bananas em suas manifestações públicas (MENGISTE, 2013; URBINATI, 2013).

A atuação de Laura Boldrini como Alta Comissária para os Refugiados da Organização das Nações Unidas entre 1998 e 2012, quando proferiu diversas críticas e acusações à Itália governada por Berlusconi e pela Liga também fez com que fosse alvo de densas manifestações agressivas promovidas sobretudo por atores políticos do partido, especialmente por Matteo Salvini. Boldrini representa a luta que envolve o domínio e a hegemonia masculina sobre o corpo e a vida das mulheres, e assim tem sido o alvo preferencial das fake News produzidas e divulgadas pela Liga e seus apoiadores. Uma das manifestações mais extremas de Salvini acerca da figura pública e do papel profissional e político de Laura Boldrini ocorreu em um comício da Liga Norte em julho de 2016 na cidade de Soncino quando, chamando a atenção do público, afirmou: "há uma sósia de Boldrini aqui” (LA REPUBBLICA, 2016, n.p., nossa tradução) ${ }^{26}$ e um correligionário levantou uma boneca inflável utilizável para fins sexuais. Salvini pega a boneca e questiona o público: "O que devemos fazer com Boldrini?", ao que a plateia responde, enfaticamente "Estupra, estupra”. A manifestação de Salvini contém uma evidente conexão entre o machismo, o sexismo e a misoginia, bem como a defesa do estupro como violência corretiva e necessária por Boldrini não ocupar o lugar que a ela seria destinado, de acordo com o ideário masculinista de Salvini e seus correligionários.

Figura 4: Cena do comício da Liga Norte em julho de 2016 na cidade de Soncino e reação no Twiter.

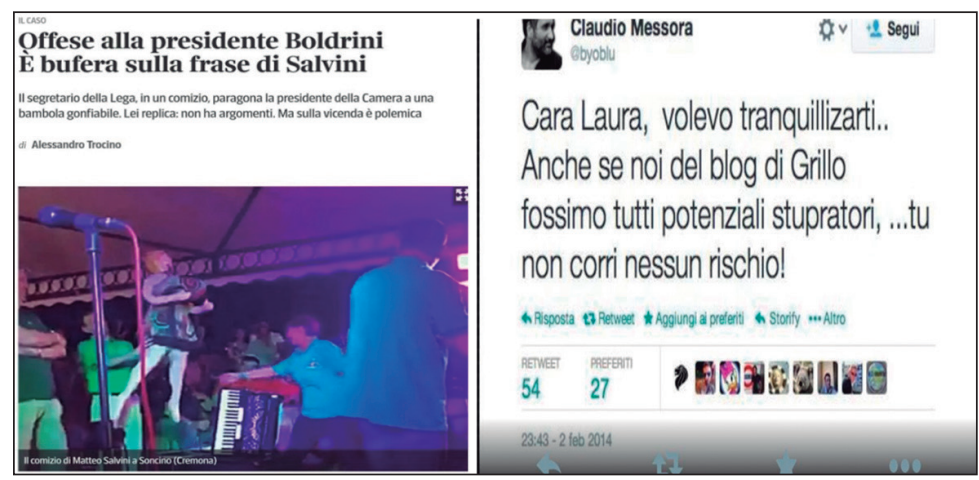

Fonte: Imagem 1: La Repubblica. Imagem 2: Twitter Claudio Messora

26 "C'è la sosia di Boldrini qui" (LA REPUBBLICA, 2016, n.p.). 


\section{Corpos que ameaçam, corpos instrumentalizados: raça e gênero no debate público sobre imigração na Itália}

Trata-se do mesmo mecanismo político utilizado por Calderoli na identificação de Kyenge ao orangotango: a utilização da piada, do escárnio e da palavra de ódio como forças semânticas que negam a política baseada em argumentos e ideias, a construção de discursos eruditos e afirma uma nova forma de manifestação estética da política: a linguagem simples e direta que não tem receio e medo de chamar "pelo nome e sobrenome os inimigos" e para eles "endereçar os humores polêmicos" (TARCHI, 2015, p.149, tradução nossa) ${ }^{27}$. A boneca inflável representa Laura Boldrini como uma prostituta ${ }^{28}$, uma palavra recorrente nas respostas dos seguidores do Twitter de Matteo Salvini, quando o líder faz profundas críticas às suas ações, ideias e posicionamentos políticos vinculados à imigração, aos direitos humanos fundamentais, aos direitos sociais e econômicos.

Para o líder da Liga, Laura Boldrini representa a defensora dos imigrantes e a traidora dos italianos, aquela que pretende promover a negação das tradições culturais e da identidade italiana e substituí-las por valores e tradições dos imigrantes africanos. As afirmações dicotômicas e maniqueístas de Salvini são frequentemente repetidas pelos seguidores do Twitter, como, por exemplo, na resposta à seguinte postagem de Salvini:

Não é "imigração": é INVASÃO, é ocupação militar, econômica, cultural e demográfica. E os cúmplices desta tentativa de SUBSTITUIÇÃO ÉTNICA, quando eu estiver no governo, serão processados e pagarão, com o próprio bolso. Boldrini irá me denunciar? Que se dane! \#stopinvasão (Twitter Salvini, 26 de Julho de 2017, tradução nossa) ${ }^{29}$.

Nos comentários dos seguidores podemos observar como a linguagem política construída através de estereótipos negativos, igualmente obscena e vulgar, agressiva e hostil, está profundamente vinculada com a opinião manifesta pelos cidadãosseguidores:

-Virginia@Virgini87207398 in risposta a@matteosalvinimi: Temos que nos libertar dessa possuída pelo demônio.

\footnotetext{
27 "per nome e cognome nemici" e "indirizzare gli umori polemici" (TARCHI, 2015, p.149).

${ }^{28}$ Evento similar ocorreu com a capitã alemã Carola Rackete, em junho 2019. No comando de uma embarcação de resgate de imigrantes, Carola foi recebida com insultos sexistas ao desembarcar na Itália, aos gritos de "prostituta", "cadela", "Spero che ti violentano sti negri. A quattro a quattro te I'hanno da infilare. Devi andare in galera", entre outros. Seu crime foi defender os imigrantes da morte por inanição, e sua pena, de acordo com os correligionários da Liga, que a receberam, deveria ser o "estupro corretivo" (MIANITI, 2019, n.p.).

29 "Non è "immigrazione": è INVASIONE, è occupazione militare, econômica, culturale e demográfica. E i complice di questa tentata SOSTITUZIONE ETNICA, quando sarà al governo, saranno processati e pagheranno, do tasca loro. La Boldrini mi denuncerà? Chi se ne frega! \#stopinvasão".
} 
- MbBgt65 luigi@MBgt65 in risposta a @matteosalvinimi: Ela será uma puta por toda a vida.

-Cocci-nella@Cocci1309 in risposta a@matteosalvinimi: Matteo, força contra esta prostituta que representa 3\% dos italianos!!!

-Virginia@Virgini87207398 in risposta a@matteosalvinimi: “Não é somente uma ofensa, mas com as suas contínuas declarações pró-imigrante e anti-italianos representa um perigo público: DEVE SER ELIMINADA”.

- Francesco Bartolomei@frances_bart)in risposta a@matteosalvinimi: “denuncia a jornalista comunista boldrini. Alguem que em um país normal já estaria na prisão ou em um instituto psiquiátrico.

-Alessandro Tamanini@AlessandroTama4 in risposta a@matteosalvinimi: "Boldrini pode ir se foder" (tradução nossa). ${ }^{30}$

O não reconhecimento de Matteo Salvini da ação profissional e política de Boldrini abrange as mais diversas esferas. Respondendo à pergunta acerca de Laura Boldrini para a Rádio Padania em 2015, Salvini afirmou que se trata da "pior presidente da Câmara da história" e que é "o nada feito mulher"31, que se comporta como "racista com os italianos" 32 . As posições públicas assumidas por Boldrini no combate à política do medo e do alarmismo, da xenofobia e do racismo contido na Liga e em outros movimentos e partidos da nova direita e, sobretudo, a defesa dos direitos humanos fundamentais dos imigrantes, da política de acolhimento digna e respeitosa, da aplicação dos direitos sociais e econômicos aos imigrantes que obtiveram à cidadania e a defesa do direito ao jus solis como Presidente da Câmara dos Deputados foram alvos não apenas de duras críticas de Salvini em suas postagens no Twitter e Facebook, como produziram muitas ameaças à sua vida e de seus familiares que foram e são ainda hoje dirigidas por simpatizantes da Liga.

\footnotetext{
${ }^{30}$ Comentários em resposta ao tweet de Matteo Salvini de 26 de Julho de 2017:

“Virginia @Virgini87207398 in risposta a @matteosalvinimi: Liberiamoci di questa invasata..."

- MbBgt65 luigi @MBgt65 in risposta a @matteosalvinimi: LEI RIMANE UNA ZOCCOLA A VITA! 曹出 - Cocci-nella@Cocci1309 in risposta a @matteosalvinimi: Matteo forza contro questa paracula cfr rappresenta il 3\% degli italiani !!!

- Virginia @Virgini87207398 in risposta a @matteosalvinimi: Non è solo un'offesa..ma con le sue continue esternazioni pro-immigrati e contro gli italiani rappresenta un pericolo pubblico: VA ELIMINATA. - Francesco Bartolomei @frances_bart in risposta a @matteosalvinimi: denuncia la giornalista comunista boldrini. Una che in un paese normale sarebbe gia' finita in galera o in istituto psichiatrico.

- Alessandro Tamanini @AlessandroTama4 in risposta a @matteosalvinimi: La Boldrini può andare a farsi fottere).

31 "il peggior presidente della Camera della storia" e "il nulla fatto donna" (LA REPUBBLICA, 2015, n.p.)

32 "razzista con gli italiani". Postagens de Matteo Salvini no Facebook e no Twitter em 26/07/2016.
} 


\section{Corpos que ameaçam, corpos instrumentalizados: raça e gênero no debate público sobre imigração na Itália}

\section{Conclusão}

A força semântica e simbólica contida na linguagem e no discurso político populista não apenas capta com crescente sucesso a atenção dos cidadãos expostos à vulnerabilidade e à incerteza, ao medo pela queda do nível de vida e às transformações do modo de vida (REYNIÉ, 2013), mas produz a construção social dos novos mecanismos de desumanização e discriminação. No início do século XXI, os slogans e as imagens políticas promovem novos processos sociais de negação da existência humana nos grupos e classes subalternos e minoritários. A linguagem vulgar e agressiva ativa energias pulsionais e estimula a ação verbal e física de desrespeito e vexame tanto para pessoas que não são reconhecidas como plenamente humanas e identificadas como ameaçadoras e perigosas à ordem da comunidade nacional orgânica e homogênea. A presença do outro - a mulher livre, a imigrante, o imigrante, o homossexual, o bissexual, o transexual - incomoda profundamente a figura do homem branco e dos seus tradicionais privilégios e papéis em todos os espaços sociais.

Não estamos apenas presenciando uma radical passagem de época em direção àquilo que não é ainda, como afirmava o sociólogo alemão Ulrich Beck (2001) em suas análises da modernidade radicalizada, mas também estamos testemunhando a articulação de forças sociais e políticas que promovem uma ampla negação das conquistas sociais criadas com liberdade e justiça social da democracia moderna e do Estado Social. Na avançada contrarrevolução em curso na Europa e no mundo, a Itália representa um dos países no qual os fenômenos morbosos da época do interregno - o termo usado por Gramsci (2000) para expor a dura passagem de época quando as forças velhas estão em processo de morte e as novas forças não conseguem atingir a hegemonia - são sempre mais cotidianos: o aumento da violência contra a mulher na casa e nos espaços públicos e profissionais, a disseminação do discurso e do crime de ódio contra as mulheres e homens imigrantes, a proliferação da linguagem política obscena e cínica, a difusão do racismo, da xenofobia e da misoginia nas redes sociais.

No curso da modernidade, os avanços e as conquistas alcançadas pelos grupos e classes sociais subalternos tendem a sofrer um processo político de reação e desemancipação, promovido pelas forças sociais que desejam manter ou aumentar o acúmulo de privilégios, direitos, bens e poder. De fato, "nem toda noite termina na aurora", como buscava apontar dialeticamente Stanislaw Jeryz Lec (2001) sobre a força da noite em promover a eliminação da existência de novas formas de identidade e relacionamentos, valores e ideias, organizações e instituições na nova ordem mundial.

O que buscamos demonstrar, ao longo desta exposição, é que no cenário contemporâneo, o debate público sobre a imigração na Itália concentra as mais 
diferentes formas de articulação do sexismo, do racismo e da violência de gênero. Fica evidente, portanto, que os corpos das mulheres e, em especial, das mulheres migrantes, é instrumentalizado, mesmo quando isto é feito sob a escusa da "proteção das mulheres" do risco de um suposto ataque do corpo estrangeiro. Em todos os exemplos mobilizados e aqui analisados, observamos que o corpo feminino que não se enquadra no ideário construído pelos atores da extrema direita, como a Liga e a Forza Nuova, é submetido a variadas formas de violência, físicas e simbólicas, com profundos impactos ao nível individual e social. Compreender, portanto, as políticas e discursos públicos sobre imigração passa necessariamente pela articulação dos diferentes marcadores sociais envolvidos, em especial raça, gênero, classe e pertencimento nacional.

\section{BODIES THAT THREATEN, INSTRUMENTALIZED BODIES: RACE AND GENDER IN THE PUBLIC DEBATE ON IMMIGRATION IN ITALY}

ABSTRACT: The public debate on immigration in Italy has been marked, since the 1990s, by the link between popular racism and institutional racism, as well as by various expressions of sexism. Voices clashing with the ongoing security paradigm have been a constant target of attacks from both social movements on the right wing as well as from political parties and exponents, the preferred target of these attacks being women who occupy prominent political positions and act for the fundamental rights of immigrants, such as Laura Boldrini and Cècile Kyenge. Migrant women have also been the target of xenophobic and racist speeches and practices, linked to misogyny and sexism. Thus, the objective of this article is to analyze the multiple forms of mobilization of racism, sexism and the instrumentalization of gender violence, pointing to the construction of stereotypes about bodies considered dangerous in the public debate on immigration in Italy.

KE YWORDS: Racismo. Gender violence. Immigration. Italy.

\section{CUERPOS AMENAZANTES, CUERPOS INSTRUMENTALIZADOS: RAZA Y GÉNERO EN EL DEBATE PÚBLICO SOBRE LA INMIGRACIÓN EN ITALIA}

RESUMEN: El debate público sobre la inmigración en Italia ha estado marcado, desde la década de 1990, por el vínculo entre el racismo popular y el racismo institucional, así como por diversas expresiones de sexismo. Las voces discrepantes 


\section{Corpos que ameaçam, corpos instrumentalizados: raça e gênero no debate público sobre imigração na Itália}

con el actual paradigma de seguridad han sido un objetivo constante de los ataques tanto de los movimientos sociales de derechas como de los partidos y exponentes políticos, y el blanco preferente de estos ataques han sido las mujeres que ocupan puestos políticos destacados y actúan a favor de los derechos fundamentales de los inmigrantes, como es el caso de Laura Boldrini y Cècile Kyenge. Las mujeres migrantes también han sido objeto de discursos y prácticas xenófobas y racistas, articulados con la misoginia y el sexismo. Así, el objetivo de este artículo es analizar las múltiples formas de movilización del racismo, el sexismo y la instrumentalización de la violencia de género, apuntando a la construcción de estereotipos sobre los cuerpos considerados peligrosos en el debate sobre la inmigración en Italia.

PALABRAS CLAVE: Racismo. Violencia de género. Inmigración. Italia.

\section{REFERÊNCIAS}

ANGEL-AJANI, Asale. Italy's racial cauldron. Immigration, criminalization and the cultural politics of race. Cultural dynamics, vol.12, 2000, p.331-352.

ANTONELLI, Giuseppe. Volgare eloquenza. Come le parole hanno paralizzato la politica. Roma: Laterza, 2017.

BASSO, Pietro. (org.) Racismo di stato. Stati Uniti, Europa, Italia. Milano: Franco Angeli, 2011.

BECK, Ulrich e BECK-GERNSCHEIM, Elisabeth. Individualization. Institutionalized Individualism and its Social and Political Consequence. London: Sage, 2001.

BERCITO, Diogo. Partido de extrema direita rompe tabu do discurso do fascismo na Itália. Folha de São Paulo. Publicado em 02 de março de 2018. Disponível em: https://www1. folha.uol.com.br/mundo/2018/03/partido-de-extrema-direita-rompe-tabu-do-discurso-dofascismo-na-italia.shtml. Acesso em: 03 abr. 2021.

BIROLI, Flávia; MIGUEL, Luís Felipe. Gênero, raça, classe: opressões cruzadas e convergências na reprodução das desigualdades. Mediações, Londrina, v. 20 n. 2, p. 27-55, jul./dez. 2015.

BOURDIEU, Pierre. A dominação masculina. Rio de Janeiro: Bertrand Brasil, 2002.

BROWN, Wendy. Undoing the Demos. Neoliberalism's Stealth Revolution. New York: Zone Books, 2015.

BURGIO, Alberto. La guerra delle razze. Roma: Manifestilibri, 2001. 
BURGIO, Alaberto. Il razzismo. Roma: Ediesse, 2012.

CAMPOS, Luiz Augusto. Racismo em três dimensões. Revista Brasileira de Ciências Sociais, vol.32, nº5, 2017, p.01-19.

CASSESE, Antonio. I diritti umani oggi. Roma: Editori Laterza, 2005.

COROSSACZ, Valeria. L'intersezione di razzismo e sessismo. Strumenti teorici per un'analisi della violenza maschile contro le donne nel discorso pubblico sulle migrazioni. Rivista Antropologia, vol.15, 2013, p.109-129.

DAL LAGO, Alessandro. Non-persone. L'esclusione dei migranti in uma società globale. Milano: Feltrinelli, 2004.

DAL LAGO, Alessandro. Populismo digitale. La crisi, la rede e la nuova destra. Milano: Raffaello Cortina Editore, 2017.

DE MAURO, Tullio."Parole per ferire". Commissione "Jo Cox" sull'intolleranza, la xenofobia, il racismo e i fenomeni di odio. Camara dei Deputati, 2017.

DEMATTEO, Lynda. L'idiota in politica. Antropologia della lega nord. Milano: Feltrinelli, 2011.

FERRAJOLI, Luigi. La criminalizzazione degli immigrati. Nota a margine della legge n.94/2009. Questione Giustizia, Franco Angeli: Roma, n.5, 2009, p.9-18.

FERRAJOLI, Luigi. Poteri selvaggi. La crisi della democrazia italiana. Roma: Laterza, 2011.

GARBAGNOLI, Sara. Italie: une contre-revolution raciste, sexiste e homophobe. AOC Analyse, Opinion, Critique. 10/09/2018. Disponível em: https://aoc.media/analyse/2018/ 09/10/italie-contre-revolution-raciste-sexiste-homophobe/. Acesso em: 03 abr. 2019.

GONZÀLES, Lélia. Racismo e sexismo na cultura brasileira. In: Buarque de Hollanda, Heloísa (org). Pensamento feminista brasileiro: formação e contexto. Rio de Janeiro: Bazar do Tempo, 2019.

GRAMSCI, Antonio. Cadernos do Cárcere, Rio de Janeiro: Civilização Brasileira, 2000.

HOCHSCHILD, Arlie Russell. Strangers in their own Land. Anger and Mouring on the American Right. New York: The New Press, 2016.

HOOKS, Bell. Feminist theory: from margin to center. London: Routledge, 2014.

ILLOUZ, Eva. Le populisme émotionnel menace la démocratie. Le Monde, 25 /07/2017. Disponível em: http://www.lemonde.fr/festival/article/2017/07/25/eva-illouz-le-populismeemotionnel-menace-la-democratie_5164585_4415198.html\#00ZpPcHzYWwU6HJd.99. Acesso em: 03 abr. 2021. 
Corpos que ameaçam, corpos instrumentalizados:

raça e gênero no debate público sobre imigração na Itália

LA REPUBBLICA. Salvini:"Boldrini, il nulla fatto donna". Solidarietà di Grasso: "Politica non si fa con offese". 11/04/2015. https://www.repubblica.it/politica/2015/04/11/news/salvini boldrini_il_nulla_fatto_donna_solidarieta_di_grasso_politica_non_si_fa_con_offese_111697950/. Acesso em: 23/04/2015.

LA REPUBBLICA. Salvini, bambola gonfiabile e offese alla Boldrini. "Sessismo indecente". Ma lui insiste, 25/07/2016. milano.repubblica.it/cronaca/2016/07/25/news/salvini boldrini-144779884/. Acesso em: 09/08/2016.

LEC, Stanislaw Jerzy. Pensieri spettinati. Bologna: Tascabili Bompiani, 2001.

MASTROPAOLO, Alfio. La mucca pazza della democrazia. Nuove destra, populismo, antipolitica. Torino: Bollati Boringhieri, 2005.

MENGISTE, Maaza. Italy's racism is embedded. In The Guardian, 10/09/2013. www. theguardian.com/commentisfree/2013/sep/10/italy-racism-cecile-kyenge-abuse. Acessado em $05 / 10 / 2013$.

MIANITI, Mariangela. Prima ti picchio poi mi perdono. Il manifesto. Edizione del 02.07.2019. Disponível em: https://ilmanifesto.it/prima-ti-picchio-poi-mi-perdono/?fbclid =IwAR1tyrhV-PUk96mwHjWpAuuRO6njHs1sEx6xUZmj8Q9zgKSA5T4NjfKErZc. Acesso em: 03 abr. 2021.

MBEMBE, Achile. Crítica da razão negra. São Paulo: n-1 edições, 2018.

PETTENÒ, Marco. Sulla violenza contro le immigrate e gli immigrati. In: BASSO, P. (org.) Racismo di stato. Stati Uniti, Europa, Italia. Milano: Franco Angeli, 2011.

PISCITELLI, Adriana. Interseccionalidades, categorias de articulação e experiências de migrantes brasileiras, Sociedade e Cultura, 11, 263-274, 2008.

POIDIMANI, Nicoletta. Ius sanguinis. Una prospettiva di genere sulla costruzione dell "italianità" tra colonie e madrepatria. Seminario Sissco Colonialismo e identità nazionale. L'oltremare tra fascismo e repubblica, Cagliari 25-27, settembre 2013.

POIDIMANI, Nicoletta. Difendere la "razza". Identità razziale e politiche sessuali nel progetto imperiale di Mussolini. Sensibili alle foglie, Roma: 2009.

REYNIÉ, Dominique. Les nouveaux populismes. Paris: Fayard, 2013.

RIVERA, Annamaria. Regole e roghi. Metamorfosi del razzismo. Bari: Dedalo, 2009.

RIVERA, Annamaria. La bela, la bestia, l'umano. Sessismo e razzismo senza escludere lo specismo. Roma: Ediesse Editore, 2010.

RODOTÀ, Stefano. Il diritto di avere diritti. Roma: Laterza, 2012. 
SABELLI, Sonia. Sessualità, razza, classe e migrazioni nella costruzione dell'italianità. Mimesis, percorsi di confine. Vol. Percorsi di genere letteratura, filosofia, studi postcoloniali n. 5. 2012, p.139-156.

SALMON, Christian. Storytelling. La machine à fabriquer des histories et à formater les esprits. Paris: La Découverte, 2008.

SARACENO, Chiara. Coppie e famiglie. Non è questione di natura. Feltrinelli, 2016.

SARACENO, Chiara. La libertà delle donne. La Repubblica, 08/01/2016a. Disponível em: http:/ricerca.repubblica.it/repubblica/archivio/repubblica/2016/01/08/la-liberta-delledonne30.html. Acesso em: 12 abr. 2016.

SCIUTO, Cinzia. Molestie e sessismo, se la "festa" degli alpini diventa un incubo per le donne. MicroMega. 10 mai 2018. Disponível em: http://temi.repubblica.it/micromegaonline/molestie-e-sessismo-se-la- $\%$ E2\%80\%9Cfesta $\%$ E2\%80\%9D-degli-alpini-diventaun-incubo-per-le-donne/. Acesso em: 10 mai. 2018.

SCOTT, Joan. Gênero: uma categoria útil para análise histórica. Educação e Realidade. Porto Alegre, vol. 20, n. 2, p.71-99, 1995.

TARCHI, Marco. Italia populista. Dal qualunquismo a Beppe Grillo. Bologna: Il Mulino, 2015

URBINATI, Nadia. Fanno paura i neri che hanno potere. In La Repubblica, 30/07/2013. https://ilmanifesto.it/fanno-paura-i-neri-che-hanno-potere/. Acesso em: 12/08/2013.

\section{Sítios eletrônico acessados e analisados}

Twitter Matteo Salvini: twitter.com/matteosalvini

Site oficial da Liga: http://www.leganord.org/

Recebido em 15/03/2020.

Aprovado em 30/11/2020. 